\title{
NuMe ALE ÎMPĂRĂȚIEI CERURILOR ÎN poezia lui Traian Dorz
}

\author{
FLORINA-MARIA BĂCILĂ \\ Universitatea de Vest din Timișoara, România \\ Names of the Kingdom of Heaven (Împărăția
Cerurilor) in Traian Dorz's poetry
}

\begin{abstract}
Our paper's objective is to analyse the expressive values of some of the names given to the biblical concept of the Kingdom of Heaven (Împărăția Cerurilor) in the poetry written by Traian Dorz, a contemporary Romanian writer, less studied, author of thousands of lines with mystical sonority and several volumes of memoires and religious meditation. In addition to highlighting their role in organising this lyrical universe (with clear references to the biblical excerpts), the paper will show how using such terms or constructions in his work concentrates authentic confessions of faith, theological truths and lines of pure wisdom, revealing, first and foremost, several aspects regarding the author's artistic belief and his conception about life and the Divinity.
\end{abstract}

Keywords: Kingdom of Heaven, grammar, stylistics, mystical-religious poetry.

\section{Introducere}

Poet de factură mistico-religioasă, Traian Dorz (1914-1989) este autorul unei opere lirice vaste, în cadrul căreia un loc aparte îl ocupă reflectarea experienței-limită a universului carceral, prin care a trecut vreme de aproape 17 ani. De altfel, așa cum se știe, pe lângă rezistența conferită de manifestările posibile ale trăirii mistice, arta și cultura (sub diversele lor manifestări) au constituit puncte de reper cu valoare etică ale celor aflați în detenție, ca act de negare a suferinței de orice gen și de afirmare a biruinței vieții, a sensului libertății prin recursul la sacru. Ca atare, dimensiunea înaltă a spiritualității a reprezentat nu numai o cale de supraviețuire, ci și un mijloc de salvare pentru marile spirite ale umanității, în ciuda condițiilor vitrege impuse de regimurile totalitare, prin revelația unor modalități specifice de a transfigura durerea și de a dobândi libertatea în spațiul carceral: credința mijlocită de rugăciunea practicată și creația (Băcilă 2016: 109).

Prin urmare, în pofida inerentelor constrângeri, de diverse tipuri, impuse într-un asemenea context, eliberarea interioară a sinelui a fost determinată, fără îndoială, de legătura specială cu Divinitatea, cu transcendența lipsită de barierele existenței pământești. Tocmai de aceea opera dorziană cuprinde sute de poezii care fac referire la ceea ce se numește „lumea de Dincolo” - năzuință a ființei umane spre libertatea 
absolută care învinge pragul apăsător al timpului, teroarea spațiului concret și sentimentul tragic al morții, spre ținta finală a identificării totale cu experiența esențială a existenței eterne.

Anticipată în textele scripturistice ale Vechiului Testament, Impărăţia Cerurilor / Împărăția lui Dumnezeu - noțiune escatologică utilizată în Biblie de zeci de ori, cu semnificații privitoare la un regat spiritual, transcendental prin obârșia lui - este tema centrală reflectată în teologia Noului Testament, ca fundament al propovăduirii lui Iisus Hristos și, în viziune creștină, ca „ipostază a dumnezeirii” (Ruști 2002: 130), ca manifestare a atotputerniciei divine, „înțeleasă drept suveranitate cerească” (Slușanschi (trad.) 1999: 116). În poezia lui Traian Dorz, ca și în textele biblice, ideea de „Împărăție a Cerurilor" presupune însă, deopotrivă, spațiul, timpul și starea existențială - imagine a desăvârșirii -, după cum o demonstrează nenumărate fragmente lirice sau chiar poeme întregi; iată, în acest sens, numai un pasaj ilustrativ: ,... Dar va fi odată, dar va fi o Ţară, / dar va fi o stare cum nicicând n-a fost, / unde totul, Doamne, numai Primăvară, / ne va fi prieten, cântec și-adăpost." (CÎnv: 23, Dintre câtă frunzăa ${ }^{1}$; de aceea, și denumirile date ei sunt dintre cele mai variate, pornind de la construcții de tip nominal până la cele având drept centru un adverb de loc ori de timp.

\section{Substantive comune / substantive proprii - nume ale Împărăţiei Cerurilor}

Referindu-ne la numele Împărăţiei Cerurilor ca spațiu al transcendenței, în creația poetică dorziană sunt de remarcat, în primul rând, grupurile nominale conținând anumite substantive comune cu rol emblematic și cu certe rezonanțe scripturistice (uneori - două sau mai multe în cadrul uneia și aceleiaşi poezii), precum și câteva nume proprii bine-cunoscute, de tipul: „Ierusalim” (CUrm: 203, La capăt de călătorie; CE: 103, Numai Tu rămâi); „Canaan” (CL: 41-43, Spre Canaan - în titlu, plus alte două ocurențe; LNS: 23, De n-ai fost pe Retezatul); „Edenul” (CÎnv: 172, Să nu renunț la luptă), „Eden” (CE: 140, Când voi reveni); „Paradis” (CÎnd: 117, Aș dori să cânt...; CVeșn: 206, Ce liniștit veniți spre mine; CS: 31, Păcat e tot ce duci prea greu; LNS: 23, De n-aifost pe Retezatul) etc.

Asemenea substantive (unele dintre ele - utilizate în diferite variante grafice, cu inițială majusculă sau nu) sunt incluse uneori în antonimii sugestive: „spre iad sau rai” (CÎnd: 112, $O$, om!...); „înspre Infern sau Paradis, / spre-ocară sau spre slavă”, „spre rai sau spre durere” (CÎnd: 113, O, om!...); „spre rai / sau iad” (CÎnd: 114, O, om!...); „între Infern și Paradis” (CA: 19, Atât de-aproape ești!); „vede iadul ce-l așteaptă, vede raiul cel pierdut” (CÎnv: 111, Fericită e nădejdea); „de-aici, ori sui spre Raiul dulce, / ori cazi spre iadul fioros” (CVeșn: 13, Nu este moarte!); „de-aici ți-alegi ori raiul slavei, / ori iadul veșnicului scrum!” (CVeșn: 13, Nu este moarte!); „1̂n raiul cel deasupra și-n

\footnotetext{
1 Spre a nu îngreuna parcurgerea trimiterilor, am optat, în lucrarea de față, pentru notarea, în text, a referirilor (cu abrevieri) la volumele (aparținându-i lui Traian Dorz) din care au fost selectate secvențele ilustrative, alături de numărul paginii / paginilor la care se află fragmentul respectiv și de titlul poeziei. Toate evidențierile din versurile citate (exceptându-le pe cele cu caractere cursive) ne aparțin.
} 
raiul cel de jos” (CBir: 104, Din câte flori frumoase); „Tu ești în Paradis departe, / iar eu, aici, într-un abis." (CBir: 193, Când îmi zâmbește El); „și din iad m-ai scos în Rai” (CUit: 127, Mulțumire-nlăcrimată); „spre iad sau paradis” (CE: 48, Alege bine - de două ori), în structuri ce vizează starea de fericire supremă pe care Divinitatea le-o oferă celor credincioși: „Tot ce Tu ne dai / este numai rai” (O: 433, Fii slăvit in cor); „casa fie-ți rai” (CNoi: 80, Scumpei surioare); „Prezența Ta mi-e tot ce-aș vrea: / un rai, un cer, un orice fie" (CNem: 90, Prezența Ta) sau la regăsirea atmosferei edenice primordiale, cu aluzii la ceea ce se numește „nostalgia paradisului”, la dorința de recuperare, în concepție creștină, a acelei inocențe cândva pierdute: „Raiul scump, / adică frumsețea nevinovăţiei” (CR: 8, Șarpele); „Raiul avut cândva întâi” (CBir: 75, O, dulce Frumusețe); „şi mă mai 'nalță-odată în zările-aurii / prin care-am fost cu Tine în primul Paradis." (CCnț: 75, Dezleagă-mă, Iisuse). În plus, atari termeni sunt implicați în sintagme nominale cu rol de substitute sau de echivalență semantică (deci, cu funcție sintactică de subiect, de nume predicativ sau de apoziție), trimițând la numele lui Dumnezeu: „Tu, Cel Ce ne-ai deschis Edenul” (CR: 18, Frumusețe); „Numele Tău Nebănuit / e-avânt și tinerețe, / e Paradisul nesfârșit / de Cânt și Frumusețe / din care Vecii curg spre Veci, / în Cânt și-n Frumusețe.” (CCm: 198, Numele Tău); „Tu ești Raiul vieții mele” (CCm: 79, Am lăsat în urmă lumea); „Hristos ni-e casă și părinți, / și ținta ultimei dorinți, / și Rai cu haruri veșnic noi, / Hristos e totul pentru noi." (CNem: 106, Hristos e totul pentru noi); „Tu-mi ești Raiul armoniei / simfoniilor divine” (CBir: 46, Tu-mi auzi, Iisus); „fie-vă Hristos - fie-vă Hristos / Raiul luminos - Raiul luminos” (CNoi: 56, Domnul fie-vă în veac); „şi nu-i alt Rai, şi nu-i alt Rai mai scump ca El” (CE: 122, Și mii de ani); „și-apoi Sus, Scump Iisus, fără-apus / fii-mi rai” (CViit: 38, Tu, Cel Drag).

\section{Grupuri nominale}

În rândul construcțiilor variate care denumesc Împărăția Cerurilor în poezia lui Traian Dorz se înscriu următoarele structuri conținând un centru de grup căruia i se adaugă:

1) Un adjectiv pronominal posesiv de persoana a II-a sau a III-a ori un pronume personal de persoana a III-a, în genitiv, antepus ori postpus: „a Ta Împărăție” (CDin: 68, Plângea tâlharul); „Împărăția Sa” (CViit: 68, Să nu te-ndoiești); „Cetatea Ta” (CUrm: 54, Lângă Poarta Veșniciei); „cetatea Ta” (CCnț: 61, Noi preamărim, Iisuse); „în Cetatea Ta, în Cetatea Ta” (CCnț: 83, Fii slăvit, Iisuse); „al Tău Ierusalim” (CVeșn: 205, Putere a lui Dumnezeu); „al Tău Ierusalim” (CUit: 143, Ține-ne, Iisuse Doamne); „al Lui Ierusalim” (CE: 66, Întoarce-ți pururi fața); „Edenul ei” (CCnț: 169, La ospăţul Dărniciei); „Raiul Tău” (CÎnv: 113, Ceata sfinților aflară); „raiul Tău” (CVeșn: 182, De raiul desfătării Tale); „Raiul Lui” (CÎnv: 107, Nu plângeți pe cel viu!); „,raiul Lui” (CBir: 193, Când îmi zâmbește El); „Țării Mele” (CCm: 138, Sfârșit e tot ce-a fost durere).

2) Un determinant în genitiv exprimând posesorul (având sau nu, la rândul lui, un alt determinant), cu referire la:

- Dumnezeu / Iisus Hristos: „-mpărăția Bunului Iisus” (CL: 30, Pasăre măiastră 
(II)); „Împărăția / lui Dumnezeu” (O: 435, Ferice-n veci); „Împărăţia Domnului Hristos” (CViit: 134, Dragostea unește); „raiul lui Hristos” (CCnț: 119, Să Se bucure de tine); „Cetatea / Împăratului Iubirii” (CÎnv: 134, Fericiți și sfinţi cei care);

- dragoste - substitut (biblic) al numelui lui Dumnezeu: „Împărăția / Iubirii” (CNem: 15, Slăvită fii, Lumină); „T, Tara Dragostei de Sus” (CÎnd: 42, De Sus); „Patria Iubirii” (CCnț: 51, De unde vii tu?);

- beatitudinea supremă și miracolul divin, ca taină a împlinirii, la superlativ, a făgăduințelor lui Dumnezeu pentru traseul existențial al celor ce I-au ascultat poruncile: „Raiul veseliei” (CÎnv: 98, Sora noastră preaiubită); „raiul desfătării Tale” (CVeșn: 182-183, De raiul desfătării Tale - în titlu, plus alte două ocurențe); „Raiul Fericirii” (CNoi: 38, Din Ziua Bucuriei... (13)); „țara frumosului destin” (CNoi: 195, Știu c-a sosit plecarea...); „Țara Păcii neapuse” (CUit: 129, Și iarăşi vii); „Țara Promisiunii” (CÎnv: 130, Cred că de-aceea m-am născut); „Patria Minunii” (CÎnv: 94, În ce vas sfânt?);

- eterna strălucire: „-mpărăția / veșnicei lumine” (CCnț: 176, Mare-i taina rugăciunii); „T,ara Soarelui Voios” (CS: 68, Se duc cocorii rând pe rând); „Patria Luminii” (CCnț: 51, De unde vii tu?);

- un alt nume (sau altele două, coordonate) din aceeași categorie, cu puternice ecouri biblice: „Împărăția Cerurilor” (CViit: 81, Nu oricine zice); „-Mpărăția Cerurilor” (CViit: 93, Să nu mergeți); „Templul Veșniciei” (CCm: 77, Cu cine să Te-asemăn?); „Țara Păcii / și-a Dragostei” (CCm: 40, Mai Sus, Iisus...).

3) Un adjectiv-atribut (antepus sau postpus, chiar la anumite grade de comparație), adesea din categoria celor devenite cvasisinonime în poezia dorziană, cu rolul de a exprima diverse caracteristici ale locului respectiv:

- sfânt: „sfânta-Mpărăție” (CCnț: 113, Când anii trec); „Sfânta-mpărăție” (CE: 120, Credință-adevărată); „Edenul cel mai sfânt” (CCnț: 40, Înstrăinaţi din nou); „Raiul sfânt” (CÎnv: 101, Fericit cel credincios); „Raiul Sfânt” (CÎnv: 110, Plânge și te tânguiește!); „Raiul Sfânt” (CVeșn: 134, Minunat Iisuse...); „acel sfânt rai” (CVeșn: 145, Cum va fi Acolo?); „Sionul Sfânt” (CBir: 50, Fă-ți prieteni pentru ceruri); „T, Tara Sfântă” (CL: 46, Mereu prin lupte; O: 109, Octombrie; CM: 59, Noi mergem); „Țării Sfinte” (CL: 42, Spre Canaan); „Sfânta Țară” (CÎnv: 99, Cei ce-au mărturisit);

- ceresc: „Cereasca-Mpărăție” (O: 145, Când Te-ai coborât, Iisuse); „Împărăţia / Cerească” (CS: 72, Tu ne-ai promis Împărăția); „cereasca-mpărăție”, „Împărăția Cerească” (CE: 17, Ferice de aceia); „cerescul Canaan”, „în cerescul, în cerescul Canaan” (CCnț: 164, Cine s-a unit cu lumea); „Cerescului Ierusalim” (CÎnd: 42, De Sus; CCm: 41, Mai Sus, Iisus...; CÎnv: 48, Oriunde doi sau trei; CBir: 78, O, Sfânt Izvor, ce nalt; CCnț: 91, Lumina Ta desăvârșită); „Edenului Ceresc” (CUit: 49, Noi știm acum); „Raiul cel ceresc” (CUit: 43, O altă viață...); „Patria Cerească” (CNem: 60, Cunoști tu oare?; CNoi: 145, Călător prin lume...);

• divin: „Raiului Divin” (CUit: 76, Plâng ochii cerului...); „Patria Divină” (CÎnd: 115, Nu-i aici...; CA: 146, O, rugăciune, apă lină!);

- etern / veșnic: „Edenului etern” (EP: 14, Tu ne-arăți, Iisuse, Calea); „tot eternul rai” (CBir: 7, Cântări de biruință); „un veșnic Paradis” (CVeșn: 220, O, Veșnicie...; MT: 
65, Colo Sus și cel mai Sus); „veșnic Rai” (CNem: 58, O, binecuvântează-i, Doamne...); „un veșnic Rai” (CÎnv: 111, Fericită e nădejdea); „Raiul veșnic” (CVeșn: 65, O, cerească armonie; CUit: 112, Răsplătește, Doamne...); „Veșnicei Cetăți” (CA: 36, O, floare a frumoasei Lucrări); „Veșnica Cetate” (CCm: 139, Sfârșit e tot ce-a fost durere; CÎnv: 169, O, de m-aşface-o iarbă);

- fericit: „acestei fericite / Împărăţii” (CCm: 39, Iisuse, Slava slavei mele); „Edenul fericit” (CUrm: 137, Cine-și mai aduce-aminte); „Raiul fericit” (CÎnv: 114, Cu sfinții odihnește); „Tara Fericită” (CE: 118, Alergarea stăruitoare);

- luminos / strălucit: „Raiul luminos” (CÎnv: 98, Sora noastră preaiubită); „Raiul luminos” (CÎnv: 101, Fericit cel credincios); „raiul luminos” (CVeșn: 62, Nu te opri), „raiul luminos” (CVeșn: 62, Nu te opri); „raiul cel mai luminos” (CVeșn: 65, O, cerească armonie); „Raiul Luminos” (CE: 65, Încarcă-ți amintirea); „Canaanul strălucit” (CL: 42, Spre Canaan); „raiul strălucit” (CVeșn: 190, Al Tău, pe veci);

•dulce: „Dulcea-mpărăție”, „Dulcea-mpărăție, Dulcea-mpărăție” (CNoi: 80, Scumpei surioare); „Ierusalime dulce” (CNoi: 127, Am străbătut oceanul); „dulcele Ierusalim” (CE: 77, Sunt tot mai lungi); „raiul dulce” (CCnț: 160, Cine laudă); „cel mai dulce rai” (CBir: 91, Dacă-ți dorești); „Raiul dulce” (CViit: 181, Surorilor iubite); „Țara Dulce” (CVeșn: 73, De la Tine vin, Iisuse); „dulcea Țară” (CNoi: 145, Călător prin lume...);

- frumos (în sensul larg al termenului, alături de sinonimele sale contextuale): „și-n ce Frumos, și-n ce Frumos Ierusalim” (CViit: 192, La Nunta Lui); „Paradisului Frumos” (CE: 20, Dar fii crin); „Edenul cel plăcut” (CUrm: 98, Va fi-n veci); „Raiul minunat" (O: 447, Pentru harul Tău);

- adjective care exprimă ideea de „întreg”: „raiul tot” (O: 419, Dragoste-a lui Dumnezeu); „tot Raiul” (MT: 25, Minune și Taină); „Raiul de răsplată plin” (CVeșn: 65, O, cerească armonie); „Raiul / plin cu cel mai dulce har...” (CUit: 114, Doamne, răsplătește-acelor);

- adjective de proveniență participială care exprimă ideea de „infinit”: „Rai Nemărginit” (CCm: 196, Ce-am cuprins din tine?); „în Raiul nesfârșit” (CUrm: 132, Cei ce-au muncit); „tot raiul nesfârșit” (CUit: 77, Lăcrimele, lăcrimioare);

- adjectivul de proveniență participială dorit: „un Eden de-atâta timp dorit” (CVeșn: 53, Spre Tine-mi duc); „Țara mult-dorită” (CBir: 32, Când trec prin stări... de două ori); „„̂n mult dorita Țară, în mult dorita Țară” (CViit: 25, Iisuse,-nvață-mă!); „în lumina umbrei Patriei Dorite” (CE: 9, Ia-mi, Iisus, odată). Această ultimă secvență lirică își găsește rezonanțe într-un vers dintr-o poezie reprezentativă a lui Traian Dorz, dedicată momentului stării de vorbă, în intimitate, cu Divinitatea: „E locul sfânt... deatâta lumină, pare beznă" (CNem: 140, E ceasul sfânt), ilustrând, totodată, semnificațiile majore ale simbolismului luminii în poezia mistică (în cazul de față - concepută în închisoare), legate de „întunericul supra-luminos [sic!] al tăcerii inițiatoare de mistere” (Pseudo-Areopagitul 1993: 147):

În acest întuneric supra-luminos [sic!] dorim ca să ajungem, şi să vedem, şi să cunoaştem, 
prin nevedere şi necunoaştere, ceea ce-i mai presus de vedere şi de cunoaştere, ceea ce-i nevederea şi necunoaşterea în sine - căci aceasta înseamnă a vedea şi a cunoaşte cu adevărat - şi să slăvim pe Cel supranatural într-un chip supra-natural [sic!], prin negarea tuturor celor existente, cum fac sculptorii, care îndepărtează tot ce împiedică vederea clară a ceea ce-i ascuns, şi care scot la iveală frumusețea cea adevărată şi ascunsă prin simpla luare. (Pseudo-Areopagitul 1993: 150).

4) Două adjective-atribute (inclusiv de proveniență participială), coordonate sau nu: „Sfânta-mpărăție / binecuvântată” (CCnț: 176, Mare-i taina rugăciunii); „Slăvita Cetate cerească” (CÎnd: 96, Răbdare!); „Cerescului Dorit Ierusalim” (CCm: 16, Cu suflet alb); „ceresc și drag Ierusalim” (CVeșn: 67-68, Mereu nainte - de patru ori, la finalul fiecărei strofe), „Ierusalim, Ierusalim, / ceresc și drag Ierusalim” (CVeșn: 67, Mereu nainte); „Ierusalimul Cel Slăvit / și Nou” (EP: 6, O, Sărbătoarea Ta); „frumosul și sfântul Paradis” (EP: 33, Iisuse, izbăvește-mi); „cel mai sfânt și dulce rai” (EP: 14, Tu ne-arăți, Iisuse, Calea); „Domnului în veci iubitei / Țări făgăduite” (CCm: 113, Porumbel cu aripi albe); „Țara frumoasă și plăcută” (CE: 111, Spre unde mergi?).

5) Adjective-atribute și determinări posesive: „-Mpărăția Ta divină” (CCnț: 91, Lumina Ta desăvârșită); „Împărăția-I sfântă” (O: 481, Să ne-nflăcăreze râvna; CUit: 93, Să vă răsplătească Domnul); „a Lui Sfântă-Mpărăție” (CViit: 77, Nu te-ngrijora); „Canaanul nostru strălucit” (CNoi: 175, Sfârșească-se frumos); „slăvita / și eterna Mea Cetate” (CVeșn: 221, Fericiți și sfinți cei care); „Sfânta Lui Cetate” (CViit: 68, Să nu te-ndoiești); „al Tău măreț Ierusalim” (CL: 63, In focul luptei); „Mărețul Tău Ierusalim”, „Frumosul Tău Ierusalim” (CCm: 40, Mai Sus, Iisus...); „Eternul Tău Ierusalim” (CCm: 41, Mai Sus, Iisus...); „Veșnicu-Ți Ierusalim” (CÎnv: 180, Primește-ne cu bunătate); „Sfântul Lui Ierusalim” (CVeșn: 184, În ziua fericirii voastre); „raiul Tău cel dulce” (CNem: 202, Doamne, iar îmi plec genunchii); „Raiul Tău cel sfânt” (CÎnv: 113, Ceata sfinților aflară); „al Tău scump rai” (CVeșn: 145, Cum va fi Acolo?); „al Lui preadulce Rai” (CUit: 90, Domnul să vă răsplătească); „Raiul Tău slăvit” (CÎnv: 106, Cât e de dulce-a Ta lumină!); „T, Tara Ta cea Sfântă” (O: 45, Iisuse, cine-a mai iubit?); „T, Tara-I minunată” (O: 411, Va veni odată...); „dulcea noastră Țară” (CÎnv: 72, Așa vom trece); „Patria mea scumpă” (CVeșn: 209, Primește-mă, Iubire!); „Patria mea sfântă” (LNS: 70, Primește-mă, Iubire).

6) Un atribut adverbial exprimat prin adverbul Sus (scris cu majusculă), însoțit de prepoziție: „Ierusalimului de Sus” (CÎnv: 99, Cei ce-au mărturisit); „Ierusalim de Sus” (CNoi: 89, Cânta-voi totdeauna); „raiului de Sus” (CVeșn: 164, Slavă, slavă, slavă); „Patria de Sus” (CL: 42, Spre Canaan); „Patriei de Sus” (CVeșn: 194, Dulci făgăduințe); „T,

7) Atribute de tipuri diferite (adjectivale, genitivale, cu prepoziție): „slăvita și frumoasa / Cerului Cetate” (CÎnv: 98, Sora noastră preaiubită); „al primăverii / Ierusalim de Sus" (CÎnv: 168, Cântarea Revederii); „întregul rai de soare” (CCm: 47, Iisuse, azi e praznic); „al dragostei depline / fericit și veșnic rai” (CÎnv: 151, Nu-i pe lume pâine bună); „Sfânta Slavei Țară” (CL: 61, Frați ostași, răsună iară); „Cereasca Slavei Țară” (CVeșn: 109, Ne-a nins peste trecut). 
De altfel, după cum am precizat, în creația lirică dorziană există numeroase poezii integral dedicate conceptului de Împărăție a Cerurilor, privită în toate trăsăturile și dimensiunile ei, poeme concepute sub forma adresării directe (deci, cu funcție conativă) și, totodată, cu substrat introspectiv. În asemenea confesiuni intime despre „nostalgia paradisului” (Crainic 1994: 243), împărtășite în stil meditativ sau de rugăciune, cu exclamații sugestive și interogații retorice, ideea poetică se construiește în jurul unor sintagme nominale situate adesea la început de vers, prin acumulări succesive în ascendență, trimițând progresiv la trăsăturile Împărăției (gloria lui Dumnezeu, iubirea absolută, beatitudinea și pacea supremă din sfera acelei transcendențe, frumusețea neasemuită, misterul comuniunii depline, lumina fără sfârșit), prin apelul la simboluri integrate explicit în imagini vizuale, inspirate din cartea Apocalipsei:

Slăvită-mpărăție-a păcii / şi-a dulcii fericiri de Sus, / tânjind de dorul după tine, / din suflet te doresc nespus. // Ce, oare, mi-a schimbat simțirea / ce altădată te ura, / iar astăzi dragostea de tine / de doru-ți, să suspine-aşa! / / O, minunată Țară-a Păcii, / străin prin lume astăzi trec, / mereu înalț spre tine ochii, / mereu genunchii mi-i aplec. // Aş vrea la sânul tău cel dulce, / când calea-mi voi sfârşi, să vin, / să-mi odihnească-n veci ființa / dumnezeiescul tău alin, // Să-mi liniştesc adânc iubirea / cu ochii fericiți privind / mereu noi forme-a' bucuriei / şi-a' frumuseții răsărind. / / În întunericul luminii / ce-nvăluie Ființa Lui, / eliberat deplin de mine, / iubirii-n veci să mă supui. // Şi-acolo-n pacea fără margini, / pe veci ce nu se mai sfârşesc, / desăvârşirea împăcării / cu veşnicia s-o găsesc! (CÎnd: 12-13, Slăvită-mpărăție-a păcii);

O, strălucită Țară cu cerul auriu, / cu ulițele scumpe de aur străveziu, / cu irizări de raze prin jerbe de culori / - cum ni se umplu ochii, chemându-ți dulcii zori! // Mai albă ca zăpada străluce fața ta, / mai cald ca tot ți-e sânul la care-n veci aş sta, / mai sfânt ca orice templu ți-e Fața Celui Drag / - o, cât de line valuri spre tine mă atrag! // De ce mă mai reține aici acest hotar, / când Dincolo e totul un zbor din har în har / şi-i totul tinerețe şi dragoste, şi Mai, / cu rugăciuni de rouă / şi răcoriri de rai? // $\mathrm{O}$, cernere de flăcări, alege-mă curat, / altarule-al iubirii, înalță-mă sărat, / sfințenie de pază, deschide-mi în cântări / - plătite socotiți-mi atâtea aşteptări! (CNoi: 122-123, O, strălucită Țară...).

De reținut, în ultimul poem citat, că simbolistica luminii (principiu al vieții și al binelui) se evidențiază și prin relația cu numele unui metal considerat adesea cel mai prețios - aurul, „simbol solar și întruchipare a perfecțiunii, a regalității și divinității” (Evseev 2007: 56), asociat, datorită caracterului său inalterabil, cu anumite concepte și valențe universale precum cunoașterea, înțelepciunea, virtutea, prosperitatea (bogăția materială și sufletească), puterea, absolutul, fericirea desăvârșită, nemurirea, puritatea / purificarea, sacralitatea etc. Astfel de sugestii se împletesc și în următoarea creație lirică realizată într-o manieră similară, cu imagini desprinse din textele biblice:

Dorită Patrie-a Iubirii, / grădina crinilor de nea, / cu ce suspinuri şi ce lacrimi, / şi doruri te-am putut chema... // Ce haruri mi-ai turnat în suflet, / de nu-mi mai aflu-n 
lume loc, / de arde-n dorurile mele / atâta dragoste şi foc, // De-am străbătut atâtea vremuri / şi drumuri fără de popas, / de harul păcii şi luminii, / şi fericirii tale-atras... // Zadarnic amăgirea lumii, / cu-al ei miraj, îmi dă ocol, / azi paşii mei mai poartă-n lume / doar trupul bătrânit şi gol. / Căci sufletul şi tinerețea, / şi tot ce-a fost mai minunat, / tu, Dulce Patrie-a Iubirii, / Acolo-n tine mi-ai luat // Şi m-ai lăsat aici să-mi ardă, / puternic, doar un singur gând: / cântând, să pot să-ți trec hotarul / c-un ceas, c-o clipă mai curând. // Mi-e dor de tot ce am Acolo, / Ținut de-argint şi de cleştar; / desprins de lumea asta, ia-mă, / să-ți trec doritul tău hotar! (CCm: 44, Dorită Patrie-a Iubirii).

Dintre aceste imagini, se remarcă sugestia albului, ca semn al regalității și al gloriei, al strălucirii transcendentale, al luminii veșnice și al inocenței, al curăției interioare de sorginte divină, al dragostei, al stării de grație, al permanentei ascensiuni spirituale, al adevărului revelat și al sfințeniei, al nostalgiei față de starea de grație edenică, al aspirației spre infinit, spre transfigurare, spre regăsirea condiției primordiale de dinaintea căderii adamice, întru redobândirea eternității. Aceste simboluri se asociază, în context, cu un motiv poetic recurent în poezia dorziană: crinul - simbol regal al purității cerești, al gingășiei, al păcii și iubirii înflăcărate, al abandonului mistic sub semnul Providenței (v. Chevalier și Gheerbrant 1995: 387-388). De asemenea, este de subliniat, în ultima strofă citată, alăturarea, în sintagma nominală evidențiată, a altor două elemente, frecvente în reprezentările simbolisticii creștine: $\operatorname{argintul~-~emblemă~}$ a înțelepciunii divine, a strălucirii care sacralizează universul înconjurător, a elevației spirituale restauratoare, a demnității regale, a bogăției sufletești - și cleștarul (termen poetic pentru cristal, simbol creștin al Fecioarei Maria, din care S-a născut Hristos, Lumina lumii), cu valențe similare, legate de ideea de limpezime și castitate; expresie a forței creatoare, prin tăria și frumusețea sa, e asociat Cerului, și prin aceasta, imaginii Ierusalimului de Sus.

8) O propoziție atributivă relativă neizolată: „Raiul pe care-l strălucești” $(\mathrm{CCm}$ : 77, Cu cine să Te-asemăn?); „Raiul unde-i numai fericire” (CUrm: 183, La căsuţa voastră); „Raiul pe unde sunt trimis” (CNoi: 160, Din câmpul cel cu stele); „Raiul în care-mi stați mereu” (CNoi: 161, Din câmpul cel cu stele); „raiul ce-l doresc” (CE: 110, Spre unde mergi?); „T, Tara ce-o dorim” (CUrm: 62, Nu se poate să nu fie); „Patria în care / ne-așteaptă Dumnezeu" (EP: 11, In fruntea luptei noastre).

9) Un atribut și una sau mai multe propoziții atributive: „Cereasca-Mpărăție / ce de atâtea mii de ani ne tot rugăm să vie” (CDr: 176, O, dacă cei buni!...); „,însă Adevărul are sfântă-mpărăția sa / unde-o dulce sărbătoare și-un tron veșnic va avea." (CUrm: 85, Adevărul n-are încă); „sfânta-mpărăție / unde fericiți să fim / toți pe veșnicie” (EP: 49, Ce-am făcut?); „Sfânt Ierusalimul dulce, / pe care de atâta cale / atâția munți ni l-au ascuns” (CNoi: 163, O, binecuvântați genunchii... ); „căci acolo-i raiul tău, / unde te-a pus Dumnezeu; / raiul tău, raiul tău / unde te-a pus Dumnezeu." (O: 475, Du-te, dragoste, și-mi stăi); „Raiul dulce unde-i strălucire” (MT: 91, La căsuța care); „să ne duci în Țara Sfântă / unde noi dorim...” (O: 29, Sus în Țara Minunată); „toată Țara Minunată / de-unde-ai așteptat odată / o crenguță verde!” (CCm: 113, Porumbel cu 
aripi albe); „Țara Sfântă ce-o dorim” (CUrm: 62, Nu se poate să nu fie); „... Se duc și-a mele dragi cântări, / rând după rând, spre Sfânta Țară / unde-n eterne desfătări / leașteaptă sfânta lor Comoară.” (CS: 69, Se duc cocorii rând pe rând); „Țara Primăverii / ce ne-aștepți în tine” (CVeșn: 177, Țara Primăverii); „Iubirea o să aibă o Patrie Slăvită / în care Adevărul, doar el, va fi-mpărat, / în care bucuria va fi desăvârșită / și Domnul Singur, Soare de-a pururi adorat.” (CUrm: 170, Va fi odată-o pace); „O, Patrie-ndelung dorită, / spre care năzuiesc mereu" (CBir: 81, O, Har primit).

\section{Concluzii}

Așa cum se observă din cele de mai sus, poemele lui Traian Dorz conținând nume ale Împărăției Cerurilor relevă, în primul rând, mărturia unei experiențe unice cu Dumnezeu a autorului lor. Denumirile respective (substantive comune / proprii ori grupuri nominale conținând atribute de diverse tipuri și / sau propoziții atributive), unele dintre ele - inedite ca organizare internă, sunt dintre cele mai variate, pornind de la structuri comune cu textele biblice, cu limbajul liturgic sau din registrul colocvial până la construcții complexe, aglomerări apozitive ce vin să contureze în ansamblu, la modul iconografic, imaginea ei emblematică.

Dincolo de valorile expresive și de însemnătatea lor în configurarea acestui univers liric (cu rezonanțe evidente în pasajele scripturistice), utilizarea unor asemenea termeni ori sintagme în opera dorziană concentrează mărturisiri de credință autentice, adevăruri teologice și învățături dogmatice, punând în lumină aspecte referitoare la crezul artistic al scriitorului și la concepția sa despre viață sau despre Divinitate.

\section{Bibliografie}

***. 1999. Dicționar enciclopedic al Bibliei. D. Sluşanschi (trad.). Bucureşti: Humanitas. Băcilă, F.-M. 2016. Dorziana - o (re)construcție a textului prin limbaj. Timișoara: Excelsior Art. Chevalier, J. și A. Gheerbrant. 1995. Dicționar de simboluri. Volumul 1. A - D. București: Artemis. Crainic, N. 1994. Nostalgia paradisului. Ediție cu un studiu introductiv de Dumitru Stăniloae. Iaşi: Moldova.

Evseev, I. 2007. Enciclopedia simbolurilor religioase şi arhetipurilor culturale. Timişoara: „Învierea”. Pseudo-Areopagitul, D. 1993. Despre numele divine. Teologia mistică. C. Iordăchescu şi Th. Simenschy (trad.). Iaşi: Institutul European.

Ruști, D. 2002. Dicționar de teme şi simboluri din literatura română. Bucureşti: Univers Enciclopedic.

\section{Surse}

CA = Dorz, T. 2006. Cântarea Anilor. Sibiu: „Oastea Domnului”.

CBir = Dorz, T. 2007. Cântarea Biruinței. Sibiu: „Oastea Domnului”.

$\mathrm{CCm}=$ Dorz, T. 2007. Cântarea Cântărilor mele. Sibiu: „Oastea Domnului”.

CCnț = Dorz, T. 2008. Cântările Căinței. Sibiu: „Oastea Domnului”.

CDin = Dorz, T. 2004. Cântările Dintâi. Sibiu: „Oastea Domnului”.

$\mathrm{CDr}=$ Dorz, T. 2006. Cântări de Drum. Sibiu: „Oastea Domnului”.

$\mathrm{CE}=$ Dorz, T. 2008. Cântările Eterne. Sibiu: „Oastea Domnului”. 
CÎnd = Dorz, T. 2004. Cântări Îndepărtate. Sibiu: „Oastea Domnului”. CÎnv = Dorz, T. 2007. Cântarea Învierii. Sibiu: „Oastea Domnului”.

$\mathrm{CL}=$ Dorz, T. 2005. Cântări Luptătoare. Sibiu: „Oastea Domnului”.

CM = Dorz, T. 1998. Cântă-mi, mamă. Sibiu: „Oastea Domnului”.

CNem = Dorz, T. 2007. Cântări Nemuritoare. Sibiu: „Oastea Domnului”.

CNoi = Dorz, T. 2008. Cântări Noi. Sibiu: „Oastea Domnului”.

CR = Dorz, T. 2006. Cântările Roadelor. Sibiu: „Oastea Domnului”.

CS = Dorz, T. 2008. Cântări de Sus. Sibiu: „Oastea Domnului”.

CUit = Dorz, T. 2008. Cântări Uitate. Sibiu: „Oastea Domnului”.

CUrm = Dorz, T. 2007. Cântările din Urmă. Sibiu: „Oastea Domnului”.

CVeșn = Dorz, T. 2007. Cântarea Veşniciei. Sibiu: „Oastea Domnului”.

CViit = Dorz, T. 2008. Cântarea Viitoare. Sibiu: „Oastea Domnului”.

$\mathrm{EP}=$ Dorz, T. 2010. Eternele poeme. Sibiu: „Oastea Domnului”.

LNS = Dorz, T. 2010. Locurile noastre sfinte. Ediția a II-a. Sibiu: „Oastea Domnului”.

MT = Dorz, T. 2006. Minune şi Taină. Imne, colinde, cântece şi plângeri cu Maica Domnului. Sibiu:

„Oastea Domnului”.

O = Dorz, T. 2005. Osana, Osana. Sibiu: „Oastea Domnului”. 